\title{
Psicólogos nos Centros de Referência em Saúde do Trabalhador
}

\author{
Psychologists in Workers' Health Reference Centers \\ Psicólogos en Centros de Referencia en Salud del Trabajador
}

\author{
Isabel Lopes dos Santos KEPPLER ${ }^{1}$ \\ Oswaldo Hajime YAMAMOTO \\ Universidade Federal do Rio Grande do Norte, Natal, RN, Brasil
}

Resumo o Centro de Referência em Saúde do Trabalhador (CEREST) é um dispositivo importante criado para disseminar as contribuições teóricas e práticas do campo da Saúde do Trabalhador (ST). Atualmente, estão cadastrados 210 CERESTs no Brasil, com diferentes características e graus de consolidação. Apesar de não compor a equipe mínima, entende-se a importância de se estudar a atuação do psicólogo, que está presente desde as primeiras experiências em alguns municípios, como São Paulo e Salvador, no início da década de 1980. Nesse sentido, o estudo tem como objetivo analisar o cenário do serviço e da política na perspectiva dos profissionais que atuam no CEREST. Trata-se de investigar, para além da atuação do psicólogo, quais as condições para uma atuação alinhada com o campo da ST. Este estudo é uma análise parcial do resultado de uma pesquisa em que se realizou um mapeamento nacional dos psicólogos que atuam no CEREST. Para tanto, foi enviado um questionário on-line em que se obteve 48 respostas de um total de 66 psicólogos contatados, com representação de todas as regiões do Brasil. Verificou-se um cenário atual com limites que se materializam em problemas cotidianos, como falta de veículo para ações de vigilância, e problemas estruturais, como falta de autonomia financeira, por exemplo. Considera-se, apesar desses limites impostos, ser possível apontar como estratégia algumas mudanças efetivas para o resgate dos princípios do Modelo Operário Italiano, em que o protagonismo dos trabalhadores no cuidado em saúde é fundamental.

Palavras-chave:

Atuação do psicólogo; saúde; trabalho.

Abstract The Workers' Health Reference Centers (CEREST) are an important device created in order to disseminate theoretical and practical contributions from the Workers' Health (WH) field of study.

There are currently 210 registered CERESTs in Brazil, with different characteristics and varying degrees of consolidation. In spite of not being part of the minimal staff, the importance of studying the psychologist's role in these centers is understood, considering they were present since the very first experiences in some cities, such as São Paulo and Salvador, in the early 1980s. Thus, the goal of this study is to analyze the service and its political scenario from the perspective of psychologists who work at CERESTs. This is about investigating, beyond the performance of the psychologists, what are the conditions for practice aligned with the WH field. This study is a partial analysis of research in which a national mapping of all psychologists working at CERESTs was made. To do so, an online questionnaire was sent, for which we received 48 responses from a total of 66 contacted psychologists, with representation from all of the geopolitical regions in Brazil. Their present situation was characterized by limits that materialize in everyday issues, such as the lack of vehicles for surveillance activities, and by more structural issues, such as the lack of financial autonomy, for example. Despite these limitations, it's possible to point to some effective changes in strategy, retrieving the principles of the Italian Worker Model in which worker protagonism in health care is fundamental.

Keywords:

Role of the psychologist; health; work.

Endereço para correspondência: Universidade Federal do Rio Grande do Norte, Campus Universitário, Centro de Ciências Humanas Letras e Artes, Departamento de Psicologia, sala 614, Lagoa Nova, Natal, RN, Brasil 59078-970, caixa-postal 1622. Telefone: (84) 3215-3590, ramal 212. Email: bel.keppler@yahoo.com.br 
El Centro de Referencia en Salud del Trabajador (CEREST) es un importante mecanismo creado para diseminar las contribuciones teóricas y prácticas en la área de Salud del Trabajador (ST). Actualmente, 210 CEREST están registrados en Brasil, con diversas características y niveles de consolidación. Aunque no haga parte del plantel básico, se entiende que estudiar la actuación del psicólogo es de fundamental importancia, ya que está presente desde las primeras experiencias en ciudades como São Paulo y Salvador desde los años 1980. Así, este estudio tuvo como objetivo analizar los escenarios de servicios y políticas en el CEREST desde la perspectiva del psicólogo. Investigamos, pues, además de la actuación del psicólogo, las condiciones para el ejercicio profesional alineado con el campo de ST. Este estudio es parte de los resultados obtenidos en investigación en que se buscó conocer los psicólogos que trabajan a nivel nacional en el CEREST. Para eso, utilizamos cuestionarios on line, del cual se obtuvieron 48 respuestas de los 66 contactos iniciales, de todas las regiones de Brasil. Se ha verificado un escenario actual con limitaciones que se materializan en problemas diarios, como la carencia de vehículos para la vigilancia y también problemas estructurales como la falta de una autonomía financiera. Aún con dichas limitaciones, consideramos que es posible apuntar algunos cambios efectivos como estrategia para el rescate de los principios del Modelo Operário Italiano donde el protagonismo de los trabajadores es fundamental para los cuidados en salud.

Palabras-clave:

Actuación del psicólogo; salud; trabajo.

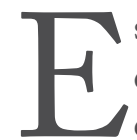

ste artigo tem como objetivo analisar o cenário do serviço e da política na perspectiva dos psicólogos que atuam no Centro de Referência em Saúde do Trabalhador (CEREST), considerado polo irradiador das políticas em Saúde do Trabalhador (ST) no Brasil. É parte de um estudo mais amplo sobre atuação do psicólogo nos CEREST, que se preocupou também em discutir a situação atual das unidades de referência.

Entende-se que mesmo que haja compromisso e compreensão da política por parte dos psicólogos, esta é inviabilizada se não há condições mínimas para executá-la. Assim, neste artigo, há dados de como os psicólogos avaliam as equipes, a intra e a intersetorialidade, as condições de trabalho, a estrutura física e a administração financeira do CEREST, bem como aspectos da gestão e da política.

Os dados anunciados pela Organização Internacional do Trabalho (OIT) de 2013 revelam uma realidade perversa, que reforça a importância de nos atentarmos a iniciativas de atuação nesse campo da ST: o trabalho mata aproximadamente dois milhões de trabalhadores por ano, número muito superior aos mortos em guerras. $^{2}$ Ainda segundo a OIT, dos casos não fatais, são 270 milhões acidentes de trabalho e 160 milhões de novos casos de doenças, anualmente.

No Brasil, segundo o Anuário Estatístico da Previdência Social, ${ }^{3}$ foram registrados 737.378 acidentes de trabalho em 2013. Esse número refere-se a trabalhadores registrados, não incluindo autônomos, como, por exemplo, empregadas domésticas, mesmo as que são contribuintes da Previdência. Outro exemplo é o caso dos trabalhadores informais. A exclusão desse setor abre para um quadro acentuado de subnotificação, considerando que grande parte da população hoje se encontra em trabalhos precários, instáveis ou mesmo desempregados (Franco, Druck, \& Seligmann-Silva, 2010).

Esse caráter negativo do trabalho (Pignati, 2013), imposto a milhares de pessoas, perpetua-se por séculos. Entende-se que as doenças e as mortes relacionadas ao trabalho não ocorrem diante de acidentes, no sentido de se tratarem como eventos imprevistos, mas como "falha metabólica do capital" (Alves, 2013, p. 15), constituinte do modo de produção vigente. Ou seja, não diz respeito a uma exceção, tal como a expressão acidente nos remete. Essa relação conflituosa entre saúde e trabalho no sistema vigente é parte da contradição estrutural da relação capital-trabalho.

As transformações ocorridas no modo de produção capitalista, tanto quanto o desenvolvimento das novas tecnologias, estiveram pouco atreladas à busca por melhores condições de trabalho e da vida humana em sua totalidade, ou mesmo uma melhor relação com o meio ambiente (Navarro \& Padilha, 2007). Pelo contrário, "manteve o trabalho alienado e degradante" (Lourenço, 2013, p. 185), ou mesmo intensificou a relação de estranhamento desenvolvendo novas técnicas de dominação.

No atual contexto neoliberal, há um movimento pendular da classe trabalhadora: por um lado, menos trabalhadores que trabalham muito, como no período da revolução industrial, marcando uma redução do

2 Estima-se, por exemplo, cem mil mortos na Guerra do Iraque, e 500 mil pessoas entre 1936 e 1939 na Guerra Civil Espanhola. Anuário Estatístico da Previdência Social. In: http://www.previdencia.gov.br/wp-content/uploads/2015/03/AEPS-2013-v.-26.02.pdf 
trabalho estável e do ideário de emprego como uma proteção social e qualidade de vida relativamente estável - amparada também pela ideia de estado de bem-estar social. Do outro lado, existem cada vez mais homens e mulheres com menos trabalho, desesperados em busca de qualquer alternativa que gere renda, ao mesmo tempo em que faz surgir, cada vez mais, trabalhos precarizados e informais (Antunes, 2007).

Especificamente tratando da saúde e das relações diretas com o trabalho, tanto a medicina do trabalho como a saúde ocupacional, que antecedem ao campo da ST, estão vinculadas a uma concepção de doença atrelada "(...) à incapacidade de trabalhar, o que a coloca [a doença] em relação com a economia e eventualmente com a criação da mais-valia e possibilidade de acumulação capitalista” (Laurell, 1982/2009, p. 9).

A legislação brasileira, no que tange à Saúde do Trabalhador, foi criada resguardada na perspectiva da saúde ocupacional, por meio do Ministério do Trabalho e da Previdência e Assistência Social, que eram conhecidos por sua política de omissão, em que o direito do trabalhador era colocado de lado a fim de resguardar os interesses empresariais (Ribeiro \& Lacaz, 1984).

O Ministério do Trabalho e Emprego, em 1972, fiscalizava a saúde e a higiene do trabalho, por meio das Delegacias Regionais do Trabalho (DRTs), que existem até hoje. Eram organismos frágeis, atuando de forma "parcial, compartimentalizada, centrada na ótica normativa e na arbitragem de conflitos, excluindo os principais sujeitos interessados, os trabalhadores, de qualquer participação na identificação de condições adversas ou na alteração de ambientes" (Medeiros, 2001, p. 10).

Ao Ministério do Trabalho e da Previdência Social cabia "dar assistência médica e prover os recursos e benefícios dos que se acidentam ou adoecem” (Ribeiro \& Lacaz, 1984, p. 32). A debilidade desses órgãos, além de seu papel claramente omisso diante das condições abusivas, tinha, por consequência, trabalhadores extremamente desamparados pelo Estado, muitas vezes reféns da empresa ou fábrica em que trabalhavam no que diz respeito aos cuidados com sua saúde.

Dessa forma, predominavam, na legislação, medidas de culpabilização da vítima, como no caso dos diagnósticos de ato inseguro (Medeiros, 2001; Ribeiro \& Lacaz, 1984) como forma de isentar a empresa de sua responsabilidade com os riscos do trabalho. Ao mesmo tempo, na década de 1970, o Brasil era tido como campeão mundial de acidentes de trabalho (Lacaz, 2013).

A medida tomada para reverter esse triste dado estatístico foi perversa. Em vez de enrijecer a fiscalização e transformar os ambientes de trabalho, o governo modificou, em 1976, a Consolidação das Leis Trabalhistas (CLT), de forma que os primeiros 15 dias depois do acidente passam a ser de responsabilidade do empregador ${ }^{4}$. Embora, por lei, qualquer acidente deva ser notificado pela empresa via Comunicado de Acidente de Trabalho (CAT) em até $24 \mathrm{~h}$ após o fato, muitos registros acabam sendo feitos depois de chegarem à Previdência. Tal medida não só contribuiu para o desamparo do trabalhador como intensificou o quadro de subnotificação. ${ }^{5}$ Esse cenário perverso do Estado, aliado aos interesses das empresas, evidencia a necessidade de os trabalhadores construírem uma alternativa de cuidado.

A ST, conhecida como alternativa operária, representa a ruptura com uma prática de assistência alinhada com os interesses da classe dominante. Origina-se no movimento operário italiano (MOI) da década de 1960, quando os próprios trabalhadores passam a formular princípios, metodologia e intervenção partindo do saber presente no cotidiano do chão da fábrica.

Representa um primeiro momento de convergência entre a análise crítica espontânea da classe operária sobre suas condições de trabalho e a necessidade, que os técnicos sentem, de colocar à disposição da classe operária todo o seu conhecimento científico, utilizado minimamente em benefício do homem (Oddone et al., 1986, p. 17).

O MOI assumiu um grande desafio de formular, por meio da investigação participativa, um saber operário e, nesse contexto, o profissional da saúde posicionou-se como aliado, atuando em uma equipe interdisciplinar, mas com o trabalhador como protagonista desse processo de cuidado.

\footnotetext{
4 Um estudo sobre a subnotificação de acidentes de trabalho em Botucatu estima que $90 \%$ dos acidentes são de caráter leve ou moderado com afastamento de até 15 dias. Cordeiro, R., Sakate, M., Clemente, A. P. G., Diniz, C. S., \& Donalisio, M. R. (2005). Subnotificação de acidentes do trabalho não fatais em Botucatu, SP, 2002. Revista Saúde Pública, 39(2), 254-60.

5 Vale frisar que, em 2015, a Previdência Social modifica novamente a lei de forma que agora passa a ser de responsabilidade da empresa os primeiros 30 dias.
} 
A síntese desse princípio está no lema não delegar (Oddone et al., 1986), seja ao patrão ou mesmo ao profissional da saúde. Mais que apenas um debate teórico e de princípios, o MOI foi propositivo na elaboração de intervenções, como é o caso da elaboração de mapa de riscos, usando como instrumento a validação consensual.

Diferentemente da medicina do trabalho e da saúde ocupacional, na ST compreende-se a saúde-doença enquanto processo, considerando seus determinantes sociais (Mendes \& Dias, 1991). Esse campo também é amparado pela perspectiva teórica da medicina social latino-americana (Laurell \& Noriega, 1989), em que o trabalho é considerado um dos principais determinantes da saúde.

Em suma, esse campo desenvolveu-se com suas particularidades em diferentes países, mas basicamente sob três pilares: o acirramento das contradições entre saúde e trabalho, a ascensão de lutas e da organização sindical, além do desenvolvimento científico e político nas universidades (Mendes \& Dias, 1991).

No Brasil, o campo da ST começou a ser discutido na década de 1970, com o fortalecimento da luta operária, no âmbito das pesquisas, sobretudo com estudos da medicina preventiva e saúde pública; no movimento sindical, que se fortaleceu com a consolidação do direito à livre organização; no movimento da reforma sanitária e nas importantes resoluções da VIII Conferência Nacional de Saúde, que teve como desdobramento a realização da I Conferência Nacional em Saúde dos Trabalhadores (CNST) no mesmo ano (1986); e na experiência prática da criação dos Programas de Saúde do Trabalhador (PST) e primeiros CERESTs, em especial em São Paulo, em meados da década de 1980 (Minayo-Gomez, 2011).

As pesquisas no âmbito da medicina preventiva e saúde coletiva, em especial, mas também outros campos, como a própria psicologia (sobretudo em casos de transtornos mentais referentes ao trabalho), trouxeram, por meio de um engajamento de intelectuais e técnicos, uma contribuição para o movimento sindical.

No campo sindical, o campo da Saúde do Trabalhador se consolida com a criação do Departamento Intersindical de Estudos e Pesquisas de Saúde e dos Ambientes de Trabalho (DIESAT), concomitante ao Departamento Intersindical de Estatística e Estudos Econômicos (DIEESE), oficialmente em 1980. O período configurou-se em uma conjuntura extremamente favorável, seja pela abertura democrática e um levante no movimento sindical, seja pelos assustadores números de acidentados nesse novo contexto de industrialização.

O intenso sofrimento e uma desesperada vontade de transformar essa realidade ecoam em uma combinação explosiva, depois de décadas de silêncio e autoritarismo nos anos da ditadura. Nas universidades, ainda prevalecia uma visão ocupacional, engajando-se timidamente na proposta que foi, de fato, impulsionada pelo movimento sindical, amparada por pesquisadores e técnicos com financiamento do próprio DIESAT.

Também nesse período, desenvolveu-se como subárea da ST o campo da Saúde Mental \& Trabalho (SM\&T), que busca romper com a visão reducionista da saúde mental, hegemonizada por questões da família e sexualidade (Araújo, 2011). A inserção da ST no campo das políticas públicas inaugura, por meio das primeiras iniciativas de PST e CEREST, em um contexto de lutas sociais também em torno da saúde, o movimento pela reforma sanitária.

Foi na década de 1980 que a saúde passou a ser um direito universal, materializando-se em um sistema único de saúde pública. Esse é um aspecto particular do Brasil em relação às políticas neoliberais nos demais países da América Latina e mesmo nos países desenvolvidos. É também particular em relação aos demais direitos sociais. O Sistema Único de Saúde (SUS) representou uma conquista, fruto de muita luta. Tal política contrapõe-se "à caridade, filantropia e benesses, como até então era tratada" (Sant'ana \& Mustafa, 2013, p. 12).

Esse movimento, para além de afirmar que a saúde deve ser direito de todos e dever do Estado, pautou também o reconhecimento dos determinantes sociais. Diferentemente do que consta na legislação referente ao Ministério do Trabalho e da Previdência Social, na Lei Orgânica de Saúde 8080, as diretrizes do SUS apresentam uma perspectiva de saúde do trabalhador que atende aos interesses da classe. No Artigo $6^{\circ}$, por exemplo, consta como diretriz a informação ao trabalhador e à entidade sindical representante, a garantia do sindicato de solicitar interdição de máquina ou setor quando este apresentar algum risco, entre outros.

No mesmo ano ocorreu a I CNST. Em 1988, quando a Constituição Federal resguardava ao SUS os cuidados com a saúde do trabalhador, intensificaram-se os conflitos com o Ministério do Trabalho e da Previdência, em especial no que tange à fiscalização. Essa relação conflituosa foi tanta que, em 1994, na II CNST, tornou-se a discussão central deliberar o que competia ao SUS e o que competia ao Ministério do Trabalho.

Foi somente no início da década de 1990 que as ações com referência no campo da ST começaram a ser sistematizadas como políticas públicas a partir da parceria feita com o governo da Itália. Esses movimentos estavam interligados e o movimento sindical esteve envolvido no planejamento, desenvolvimento e execução 
das ações. No entanto, desde o início, revelou seu caráter marginal mesmo dentro dos movimentos, atuando como um gueto da saúde do trabalhador (Dias \& Hoefel, 2005) no interior da luta pela reforma sanitária, que defendia a importância de pautar a centralidade do trabalho e/ou o trabalho como determinante social.

Como síntese das discussões nas Conferências Nacionais de Saúde e nas CNSTs, elaboradas pelo movimento sindical e popular e por pesquisadores vinculados ou não à academia, a ST passou a ser adotada como uma diretriz do SUS, consolidando as iniciativas já existentes. Em 1991, a partir de uma primeira proposta de Plano de Trabalho em Saúde do Trabalhador no SUS, é que a prática do CEREST começou a ser sistematizada com o intuito de fortalecer o campo, investindo na formação dos profissionais da saúde. Até 1994, o CEREST era tido como "expressão da luta organizada dos trabalhadores por melhores condições de vida e de trabalho e da ação de tutela da saúde dos cidadãos pelo Estado" (Dias \& Hoefel, 2005, p. 822).

Ao final de 2002, a Rede de Atenção Integral à Saúde do Trabalhador (RENAST) foi criada e adotada como principal estratégia da Política Nacional em Saúde do Trabalhador. A criação da RENAST foi um grande marco para a política pública em Saúde do Trabalhador no Brasil, visando articular os diferentes serviços e diferentes níveis de gestão do SUS, para a "disseminação dos princípios e práticas do campo da Saúde do Trabalhador no SUS” (Jacques, Milanez, \& Mattos, 2012, p. 370). Assim, atribui-se ao CEREST, enquanto unidades de referência em ST, o caráter de "polo irradiador". Sua função é promover ações relacionadas a vigilância, assistência, educação em saúde e produção de informação em saúde do trabalhador.

Passados mais de 25 anos de políticas públicas em ST, há um vasto acúmulo de balanços sobre essa experiência, seus limites e desafios. Em 2005, sobre os desafios de implementação da RENAST, Dias e Hoefel (2005), afirmam que "a Saúde do Trabalhador tem sido colocada ora no âmbito da estrutura da Vigilância, ora na Assistência ou em outras instâncias administrativas do SUS, dependendo do formato institucional vigente" (p. 819). Esse elemento reforça a importância de estudos como este, pois, mesmo passado tanto tempo, os CERESTs ainda se encontram em diferentes graus de consolidação e, mais do que isso, possuem diferentes ênfases de acordo com a política regional.

Os limites das políticas públicas em ST correspondem aos limites da consolidação do SUS. Apesar de fruto de um processo construído por diversos movimentos e pela sociedade civil, o SUS encontra dificuldade de concretizar seus princípios e diretrizes, não apenas o do trabalho como determinante social. A lógica centrada nos hospitais, resultando na superlotação, no atendimento médico em detrimento a uma equipe multiprofissional, o modelo curativo, individual e por vezes biologicista, são alguns dos exemplos.

Além disso, coloca-se centralmente como um obstáculo a relação público-privada, presente desde o início, e que se intensifica trazendo prejuízos ao serviço - valoriza-se equipamentos de complexidade alta, mais caros, em detrimento às unidades básicas, além de precarizar as relações trabalhistas, mediante preferência de contratos via terceirização. Nesse aspecto, o exemplo mais recente é a criação das Empresas Brasileiras de Serviços Hospitalares (EBSERH), que gerencia os hospitais universitários.

Assim, ainda que o SUS tenha sido consolidado como fruto de pressão popular, sua implantação não consegue ser efetivada diante da preferência do Estado em responder aos interesses econômicos do grande capital, à revelia da efetivação de direitos sociais.

Referente a ST, outros obstáculos são apresentados, como a dificuldade de cumprir seu aspecto regional, muitas vezes centralizando suas ações apenas no município de referência, a vigilância com um caráter meramente fiscalizador sem diferenciar da ação do Ministério do Trabalho e Emprego, a fragilidade da rede do SUS, a equipe que desconhece as premissas do campo e o papel secundário dos trabalhadores (Santos \& Lacaz, 2011). Como fruto da luta do movimento sindical dos trabalhadores rurais, foi aprovada a criação de dez CERESTs rurais no Brasil. Ainda assim, esse processo avança muito lentamente, de forma que a maioria está estagnada e não se desenvolve.

A relação entre Ministério da Saúde, da Previdência Social e do Trabalho também varia entre as regiões: ora é conflituosa, ora é articulada. Independentemente de uma boa relação, três órgãos para amparar sobre o tema da Saúde do Trabalhador faz com que, por exemplo, dentro do mesmo Estado se produza duas bases de dados, uma pela Previdência, outra pelo SUS, referente aos acidentes de trabalho - e em ambas há lacunas que implicam a subnotificação.

Com relação aos psicólogos, atuam nos CERESTs desde a sua origem. Em 2008, o Conselho Federal de Psicologia (CFP) publicou o documento elaborado pelo Centro de Referência Técnica em Psicologia e Políticas Públicas (CREPOP), "Saúde do trabalhador no âmbito da saúde pública: Referências para a atuação do(a) 
psicólogo(a)". Esse material, que se apresenta como uma espécie de "manual” do psicólogo no campo da ST, sistematiza as atividades do profissional no campo.

Esse documento afirma que "a relação trabalho/subjetividade ainda não foi devidamente reconhecida nesse contexto [formação do psicólogo], o que representa uma séria barreira para a atuação desse profissional em todas as áreas, sobretudo no campo da Saúde do Trabalhador" (CREPOP, 2008, p. 44). Nesse sentido, esta pesquisa contribui tanto para outros estudos sobre o CEREST e as políticas em ST como para aqueles referentes a experiências dos psicólogos em CERESTs (Toldrá et al., 2010; Salerno, Mirim, \& Sabino, 2011).

\section{MÉTODO}

Para a realização deste estudo, fez-se, inicialmente, um mapeamento dos psicólogos que atuam nos CERESTs no Brasil, por meio de contato telefônico. Questionava-se sobre a presença ou não de psicólogo na equipe e, em caso afirmativo, era feito o convite para participar da pesquisa.

Aos que aceitaram participar, foi enviado um questionário on-line com 32 perguntas organizadas em quatro blocos: perfil do psicólogo, funcionamento do CEREST, condições de trabalho do psicólogo e atividades do psicólogo. Para acessar as perguntas era obrigatório assinalar a anuência com o Termo de Consentimento Livre e Esclarecido, em consonância com os procedimentos éticos vigentes. A amostra final foi composta por 48 psicólogos que responderam ao questionário.

\section{RESULTADOS E DISCUSSÃO}

\section{Consolidação regional do CEREST: Vínculo com atividades econômicas e controle social}

O primeiro conjunto de dados obtidos por meio do questionário diz respeito à consolidação regional do CEREST. Dos respondentes, 41 afirmam a existência de relações das principais atividades econômicas com o público do CEREST, ao passo que 6 negam (e 1 se absteve de responder). Com referência ao setor da economia com a qual identificam vínculos, a maioria (32 psicólogos) aponta a atividade industrial, seguida de rural (17 psicólogos). Com relação à combinação de ramos, industrial e rural foi a mais frequente (7 psicólogos), seguida de industrial e serviços (5 psicólogos). Dos CERESTs rurais, consolidados recentemente, apenas um alegou possuir psicólogo. $\mathrm{Na}$ resposta ao questionário, o psicólogo não aponta nenhuma especificidade da unidade em relação às demais.

Como discutido anteriormente, o campo da ST desenvolve-se no contexto urbano, acompanhando o processo de industrialização. As limitações em alcançar o contexto rural são nítidas. Apenas um questionário faz referência à questão do campo, ainda de forma vaga sobre como funcionou. "Participar de ação de vigilância nas escolas rurais do município." (R44)

Esses limites estão vinculados, talvez, com as dificuldades de cumprir a abrangência regional do CEREST. Falta de veículos e duplo emprego são elementos que apontam para a dificuldade de cumprir o caráter efetivamente regional e, mesmo, às demandas de um contexto rural, que exige maior deslocamento da equipe. A resposta transcrita a seguir exemplifica tais dificuldades:

O carro, doação do Ministério Público do Trabalho, fica a maior parte do tempo a serviç̧o do município-sede do CEREST, com o carro sendo disponibilizado apenas duas tardes na semana, o que inviabiliza o trabalho nos outros municipios de abrangência. (R7)

Hoje, os CERESTs acabam concentrando as atuações no município sede, embora, em alguns casos, competiria a alguns CERESTs a cobertura de até 30 municípios (Santos \& Lacaz, 2011). Sem levar em consideração as condições objetivas para concretizar tal expectativa, esse número, que já seria alto, é agravado pela precária estrutura material e de pessoas dos serviços.

Outro dado que ajuda a compreender o grau de consolidação do CEREST é a presença e frequência de reuniões da Comissão Intersetorial em Saúde do Trabalhador (CIST). Segundo as respostas, em 16 CERESTs a CIST se reúne ao menos uma vez por mês; em três, uma por semestre; e em seis conforme a demanda. Em 15 CERESTs não há CIST e 7 psicólogos não sabiam responder (um deixou em branco).

Nenhum dos psicólogos citou a CIST nas questões abertas. O que mais chama a atenção é que em nenhuma das respostas o trabalhador aparece como protagonista ou, ao menos, parte das atividades do CEREST. Quando 
citada alguma necessidade de intensificar a relação, os Ministérios do Trabalho e Emprego, a Previdência Social ou outras unidades de saúde são citados como o matriciamento da atenção básica ou maior relação com o Centro de Atenção Psicossocial (CAPS). Mas o trabalhador, curiosamente, continua sendo um sujeito invisível. Esse "dado ausente" talvez seja o elemento mais significativo para entender os impasses de como hoje o CEREST está afastado da proposta de origem, e será abordado novamente em estratégias.

\section{Equipe}

Por se tratar de um campo com diversos profissionais, a atuação em equipe é bastante importante, e isso apareceu intensamente nas respostas. Embora não tenha sido detalhado qualitativamente como funcionam, foi indicado que 40 CERESTs realizam reuniões de equipe, sendo 28 regularmente e 12 conforme a demanda. Apenas seis responderam que não realizam e um não respondeu. A relação entre a equipe é considerada muito boa por 21 psicólogos, 4 são indiferentes e 1 psicólogo apenas avaliou como ruim (um psicólogo não respondeu).

As respostas abertas confirmam esse parecer favorável em relação às equipes: 30 psicólogos apontaram aspectos positivos sobre a equipe - a referência mais frequente nessa questão. Em relação aos aspectos negativos, o tema também é bastante abordado, citado por 19 psicólogos, mas mencionando a sua dimensão reduzida, o que, na realidade, corrobora a valorização do trabalho em equipe. Na Tabela 1 é possível ver os subtópicos mais abordados pelos psicólogos com relação aos aspectos positivos e negativos.

TABELA 1. Aspectos positivos e negativos citados pelos respondentes em relação às equipes do CEREST

$\begin{array}{ccc}\text { Aspectos citados } & \text { Aspectos positivos } & \text { Aspectos negativos } \\ \text { Integrada* } & 14 & - \\ \text { Capacitação } & 15 & - \\ \text { Motivação } & 10 & 2 \\ \text { Relacionamento } & 8 & - \\ \text { Autonomia } & 3 & 14 \\ \text { Composição } & 2 & - \\ \text { Planejamento } & 1 & \end{array}$

Nota.*Integrada (conforme designação dos respondentes, multiprofissional ou interprofissional).

A capacitação foi ressaltada tanto no sentido de a equipe ser competente como no de fazer cursos ou, mesmo, estudos de caso realizados dentro da equipe. Também foi citada a autonomia (3 psicólogos), o fato de estar completa (dois psicólogos) e a capacidade de fazer planejamento (1 psicólogo).

A equipe trabalha de forma multidisciplinar, com isso facilita muito na perspectiva de crescimento profissional e no resultado para os trabalhadores. (R4)

A formação da equipe, a interdisciplinaridade, o envolvimento e a compreensão do que é CEREST e qual o nosso papel no SUS. (R6)

\section{Equipe multiprofissional facilitando o estudo de casos e acompanbamento adequado. (R29)}

Nos aspectos negativos, o tema apareceu 19 vezes, sendo 14 por ser insuficiente ou incompleta. A Portaria 1679/02 regulamentou uma equipe mínima para os CERESTs e foi ampliada na Portaria 2.437/05, com exigência de dez funcionários (ensino superior, médio e técnico) no caso dos regionais e 15 nos estaduais, sendo 
obrigatórios auxiliares de enfermagem, médicos e enfermeiros. De acordo com o $2^{\circ}$ Inventário RENAST de 2010-2011, 39,5\% dos CERESTs encontram-se de acordo com o que a Portaria exige.

Ainda assim, cumprir a equipe mínima reconhecida pela Portaria não significa ser suficiente ou adequada à demanda local (Machado et al., 2013). A própria Portaria impõe limites ao restringir os profissionais e técnicos obrigatórios quando reforça a lógica de saúde centrada na assistência, em específico, na figura do médico (Santos \& Lacaz, 2011).

Outro elemento foi a ausência, ou a insuficiência, de capacitação para a equipe, articulada ou não com o entendimento sobre o CEREST:

Faltam cursos de capacitação que melhor preparem tais profissionais para desenvolver açôes, pois desde 2011 estou no CEREST e somente eu que vou às reuniôes, porém cursos mesmo nunca foi disponibilizado pelo estado. (R14)

Falta de formação, pois a saúde do trabalhador envolve um conhecimento especializado, técnico e interdisciplinar; muitos protocolos para "dominar" conhecimento e desenvolver intervençôes e responder demandas; falta de autonomia da gestão, inclusive para uso do recurso disponivel; ambiguidades no entendimento do que é o papel do CEREST; más condições de trabalho; distanciamento entre CERESTs [isolamento] e falta de participação na esfera macro [discussão da implementação da Política Nacional da Saúde do Trabalhador e da Trabalhadora]. (R46)

Entende-se que o debate em torno do adequado funcionamento da equipe tem impacto direto nas condições de trabalho do psicólogo e demais membros, bem como no desempenho do serviço. $\mathrm{O}$ fato da equipe ser citada por mais da metade dos respondentes como um aspecto positivo revela ser algo importante e apreciado pelos profissionais. Se, por um lado, as equipes parecem cumprir um papel de fortalecer e garantir condições favoráveis para um bom trabalho, o fato de ser insuficiente e, por vezes, não capacitada e sem o conhecimento do campo, dificulta uma boa intervenção.

\section{Intrasetorialidade}

Segundo os respondentes, apenas três CERESTs não possuem relação com outra unidade do SUS, sendo 24 unidades com articulação conforme a demanda e $20 \mathrm{com}$ diálogo considerado frequente. A prevalência, como é possível verificar na Figura 1, é de hospitais (33) e de Unidades Básicas de Saúde (34). Os CAPS foram assinalados apenas para 18 CERESTs.

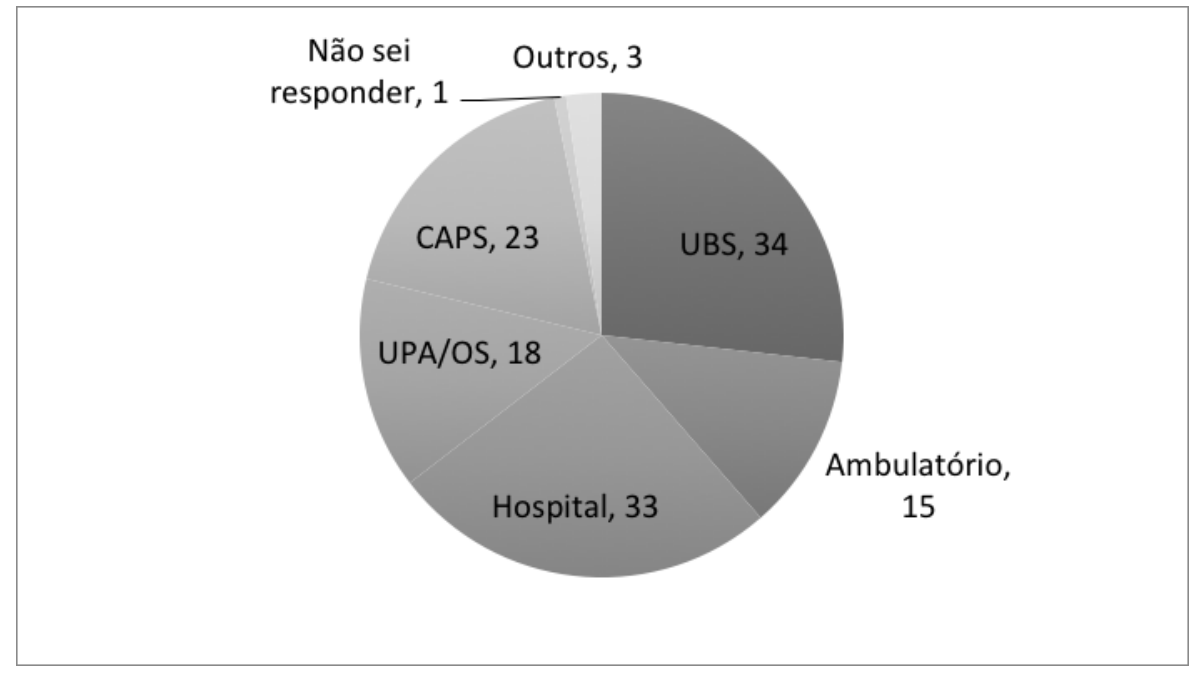

FIGURA 1. Instituições que fazem parte da rede intrasetorial citadas pelos respondentes

A relação com unidades, como Unidades de Pronto Atendimento (UPAs), e hospitais que recebem emergências de acidentes (como amputação, por exemplo) são importantes para que o CEREST possa planejar as suas ações. Nesse sentido, seria esperado que o CEREST, se estivesse consolidado, estabelecesse alguma relação com todos esses serviços. Assim, acrescenta-se como dado para essa discussão o fato de uma maioria 
considerável (39 unidades) adotar um funcionamento de serviço com o sistema porta aberta, ou seja, de acolhimento dos trabalhadores. Apenas oito realizam atendimento apenas mediante encaminhamento.

Esse dado retoma a discussão sobre qual o papel do CEREST: concentrar todas as questões de saúde do trabalhador, como um gueto, ou cumprir um papel de polo irradiador para toda a rede. Como forma de se aproximar dessa atuação de retaguarda técnica e de referência para a rede, com a formação da RENAST, o CEREST deixa de ser um serviço de porta aberta.

Nesse sentido, o apoio matricial dos CERESTs é uma ação bastante importante. Esse tema foi abordado no tópico de aspectos negativos, referente à dificuldade de articulação da rede; no tópico de estratégias para avançar, em especial com atenção básica e a necessidade de fazer matriciamento. No tópico de intervenção em que atingiu parte do seu objetivo, foi citada a realização de matriciamento na rede básica.

Os CAPS ainda aparecem com uma baixa relação, mas, segundo o questionário, é possível apontar uma tendência a intensificar essa aproximação. Em três respostas a relação com o CAPS aparece como estratégia para melhorar a atuação do psicólogo. Essa discussão será retomada no tópico sobre as estratégias.

No que tange à intersetorialidade, 26 psicólogos responderam que essa relação ocorre conforme a demanda, e 23, em uma relação de parceria.

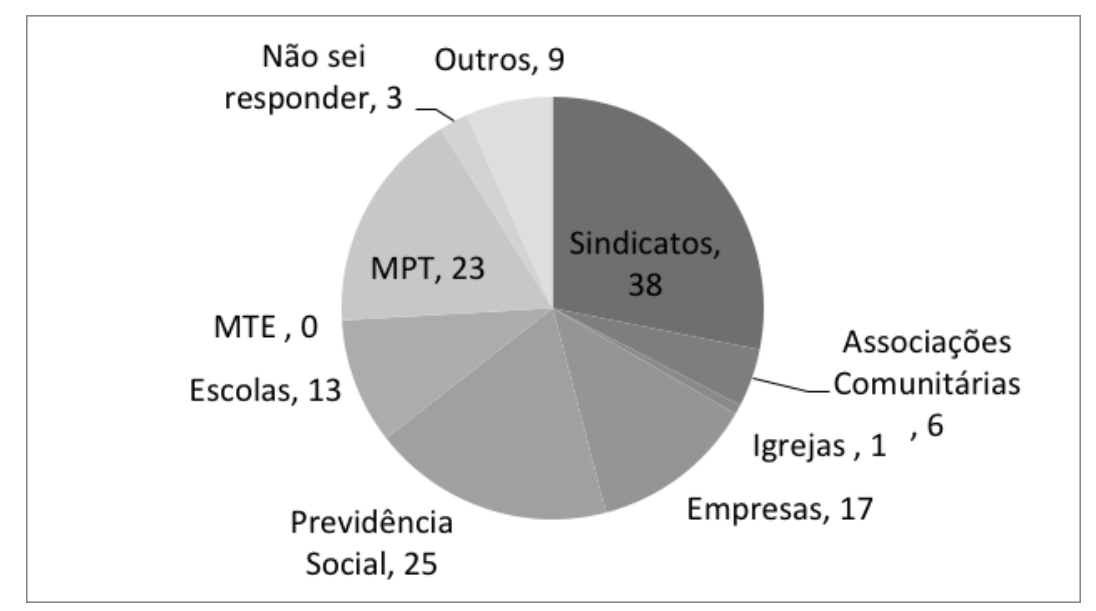

FIGURA 2. Instituições que fazem parte da rede intersetorial citadas pelos respondentes

Na Figura 2, observa-se que o sindicato é a instituição que mais CERESTs assinalaram possuir relação (38). Em seguida, a Previdência Social é assinalada em mais da metade das respostas, seguidos do Ministério Público do Trabalho (MPT) (23) e do Ministério do Trabalho e Emprego (MTE) (16). As universidades, que não constavam no questionário, foram citadas espontaneamente por três psicólogos na alternativa "outros", além da Fiocruz e de um Instituto de Psiquiatria vinculado à Universidade.

Anteriormente, discutiu-se a relação conflituosa do MPT, MTE e o Ministério da Saúde com a ST. No entanto, nas questões em que tais ministérios foram citados, pareceu existir uma relação de cooperação entre os órgãos, ou disposição para tal, como é o caso da R40: "Na minha realidade de trabalho, seria uma estratégia, trabalhar mais próximo ao Ministério do Trabalho e Emprego assim como da procuradoria." A R38 também cita como aspecto positivo "Parcerias com diversos segmentos [MPT, MPE, INSS e outros...]".

Apesar de o sindicato ter sido a instituição mais assinalada, apenas uma resposta cita uma ação conjunta tendo o sindicato como referência. O tema não é abordado nas demais questões, o que reforça a discussão feita sobre a ausência da participação dos trabalhadores nas ações do CEREST.

\section{Condições de trabalho}

Não foi perguntado especificamente sobre remuneração, mas foi mencionado como estratégias para melhorar e no tópico sobre aspectos negativos, foi citado o salário baixo, contratos precários e a questão da dupla jornada ou jornada excessiva, por diferentes respondentes. Ainda que menos de dez psicólogos tenham apontado espontaneamente, outro dado que pode indicar a baixa remuneração é o fato de terem duplo emprego. Um dos psicólogos respondeu que "os contratos são precários [sem direito a férias remuneradas, $13^{\circ}$ salário]". (R40) 
Pensar em condições precárias em um serviço de saúde, em especial um Centro de Referência em Saúde do Trabalhador é uma triste ironia do Estado. Para além das questões empregatícias, foi abordado também a questão da segurança ao redor e calor como elementos negativos que prejudicam o trabalho.

\section{Estrutura do CEREST e finanças}

As respostas que abordaram de forma mais precisa a questão da estrutura, apresentaram um quadro crítico. A questão da localização é um elemento também relevante, que reflete na materialização do caráter marginal do CEREST.

A localização dificulta o acesso dos usuários, pois necessitam de pegar dois ou mais ônibus para chegar ao local. Ainda não possui viatura própria para deslocamento da equipe para vistorias, inspeçôes, palestras, etc. (R43)

Referente à estrutura, a pergunta fechada mais relacionada ao tema dizia respeito à avaliação do profissional quanto à estrutura do CEREST. A maioria considerou adequada ou parcialmente adequada.

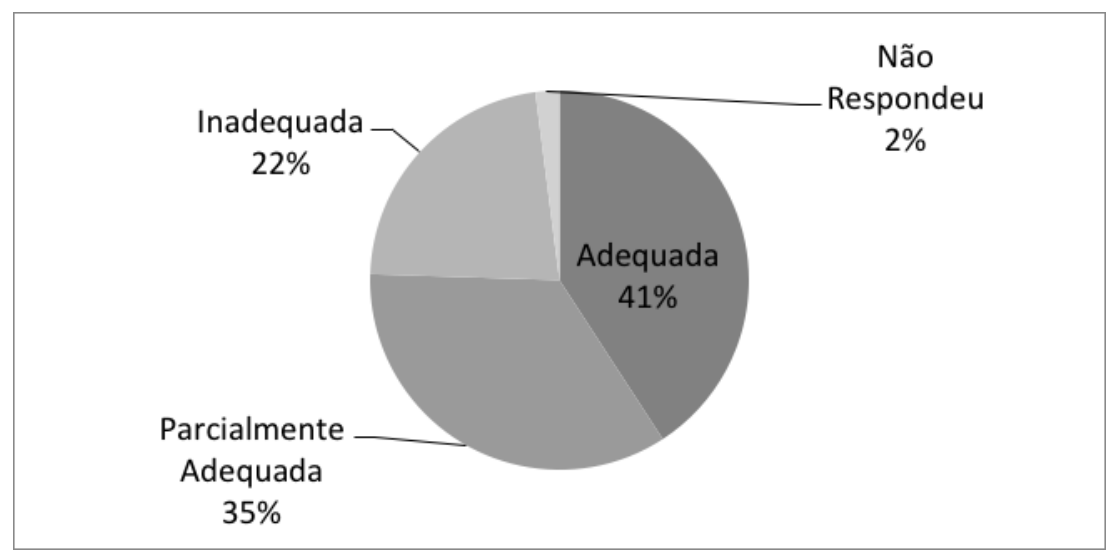

FIGURA 3. Avaliação da estrutura do CEREST

O tema foi abordado espontaneamente pelos psicólogos na questão aberta, sobre aspectos positivos e negativos. A sistematização dos aspectos citados referente à estrutura e finanças podem ser visualizados na Tabela 2 .

TABELA 2. Aspectos positivos e negativos citados pelos respondentes em relação à estrutura e finanças do CEREST

\begin{tabular}{ccc}
\hline Aspectos citados & Aspectos positivos & Aspectos negativos \\
Prédio (estrutura/localização) & 8 & 8 \\
Materiais e equipamentos & 6 & 6 \\
Veículo & 1 & 5 \\
Financeiros/Administrativo & 3 & 10
\end{tabular}

A ausência de veículos é um dado que interfere na cobertura dos municípios de abrangência e nas ações de vigilância, talvez sendo um dos exemplos mais críticos de como as condições objetivas podem determinar o cumprimento ou não da política do serviço.

Um outro exemplo nesse sentido é o que os psicólogos mencionaram com relação à administração financeira do CEREST. Dez psicólogos abordaram o tema da administração e finanças e, desses, seis associaram diretamente à ausência de autonomia e ao procedimento burocrático, muitas vezes lento e com muitos entraves. Isso dificulta as viagens para capacitação, a aquisição de materiais necessários, etc. Alguns psicólogos associaram esses chamados entraves a uma questão política da gestão de ignorar ou mesmo propositalmente banir as ações voltadas à saúde do trabalhador.

Gestão e política

Esse tema foi um balizador relevante para que haja condições favoráveis ou desfavoráveis para a atuação do profissional. Tanto em aspectos positivos ou em aspectos negativos, o tema foi abordado com expressões como valorização e compreensão (ou não) sobre a saúde do trabalhador. Alguns psicólogos chegaram a explicitar um entrave político por se tratar desse tema. A resposta abaixo aponta um cenário bastante preocupante: 
Falta de autonomia de acesso ao financeiro destinado ao CEREST que nos impede de realizar qualquer investimento em ST; recusa por parte da secretaria de saúde em possibilitar participação e financiamento em eventos referentes a politicas de saúde do trabalhador, falta de apoio financeiro para a realização de açóes educativas em ST, não reconhecimento da importância do trabalho realizado pela equipe e falta de compromisso, implicação da secretaria com o CEREST. (R15)

Ao todo, 16 psicólogos citaram aspectos negativos de desvalorização e entraves políticos da gestão, ou mesmo não conhecimento das políticas em saúde do trabalhador. A falta de monitoramento, pela gestão municipal, estadual e até mesmo nacionalmente via RENAST também foi citado. Para além de um aparente e proposital bloqueio político para as ações em saúde do trabalhador, houve exemplos de precarização que levam a coordenação a apresentar dificuldades na gestão do serviço.

O funcionamento dos outros CEREST regionais conforme preconiza a RENAST. O fato da coordenação do CEREST Estadual não ser remunerada e a chefe do Núcleo Estadual de Vigilância em Saúde do Trabalhador, ter que se ocupar também das atribuiçôes de coordenação do CEREST resulta numa densidade de demandas para pessoa, o que acaba sendo prejudicial à Politica de Saúde do Trabalbador e à trabalhadora que assume as duas funções. (R36)

Uma das respostas abordou também as dificuldades presentes entre realizar ações nos municípios. Esse é um desafio existente no CEREST, considerando que sua distribuição regional faz com que a unidade tenha que lidar com diversas prefeituras distintas, ao passo que a gestão do equipamento fica a cargo do município sede (Santos \& Lacaz, 2011).

Se no aspecto negativo é um tema relevante, apresenta-se também nos aspectos positivos como algo que facilita no trabalho. Nesse sentido, onze psicólogos citaram positivamente o papel da gestão. As respostas variaram entre ressaltar uma boa relação, pela gestão estar alinhada com a política em saúde do trabalhador, pelo fácil acesso, por apoiar ações de capacitação ou por funcionar de forma participativa.

Este artigo abordou alguns aspectos do cenário atual nos CERESTs. Atenta-se nas considerações finais, sobretudo, aos elementos dos últimos tópicos, de estrutura e finanças e com relação à gestão. Compreende-se que estão bastante relacionados com os limites presentes nas políticas sociais em geral. É preciso entender esses problemas para além de uma simples "falha" administrativa, mas diante de uma reflexão mais ampla sobre as políticas sociais no Estado capitalista. Assim, tal constatação nos leva a relativizar a compreensão de que o CEREST e as políticas em ST não funcionam como deveriam.

$\mathrm{Na}$ perspectiva dos trabalhadores, de fato, o serviço está distante de responder às demandas que a condição de tamanha precariedade - ou mesmo barbárie - presente no cotidiano daqueles que dependem da venda de sua força de trabalho para manutenção da própria vida e de seus familiares. No entanto, na perspectiva da classe dominante, e do Estado enquanto administrador de seus interesses, tal política talvez esteja funcionando exatamente como o esperado: não funcionando. Esse estudo, nesse sentido, corrobora com o preciso questionamento que Costa, Lacaz, Jackson-Filho e Vilela (2013) apontam:

Assim, cabe a indagação: como podem se institucionalizar ações no campo ST que se situam no enfrentamento das contradições capital-trabalho se a política real, que conjuga interesses do Estado e do capital, pauta-se pelos princípios do neoliberalismo (p. 16).

Essa questão, que pode ser tomada como negativa, serve aqui para permitir discutir, afinal, quais ações possíveis estão colocadas aos profissionais de saúde e aos trabalhadores em geral para permitir ações efetivas, e não apenas pontuais, superficiais e ineficientes.

Com respeito ao que é possível fazer, entende-se que muitas das dificuldades encontradas em como conseguir melhorar a intervenção do psicólogo, desde questionamentos de sua prática até a conquista de melhorias do serviço, podem ser mudadas se resgatado um princípio fundamental da ST: a participação dos trabalhadores.

Não é coincidência que as principais conquistas de direitos sociais estão contextualizados a momentos marcados por lutas e movimentos importantes da classe trabalhadora organizada. Os princípios da ST, como alternativa operária, apresentam nitidamente ao profissional da saúde, e no caso do estudo, os psicólogos especificamente, o papel de aliados a esses trabalhadores. 


\section{REFERÊNCIAS}

Alves, G. (2013). Prefácio: O adoecimento do trabalho como falha metabólica do capital. In E. A. S. Lourenço \& V. L. Navarro (Orgs.), O avesso do trabalho III (pp. 13-18). São Paulo: Outras Expressões.

Antunes, R. (2007). Dimensões da precarização estrutural do trabalho. In G. Druck \& T. Franco (Orgs.), A perda da razão social do trabalho - Terceirização e precarização (pp. 13-22). São Paulo: Boitempo.

Araújo, T. M. D. (2011). Revisão de abordagens teórico-metodológicas sobre saúde mental e trabalho. In C. Minayo-Gomez, J. M. H. Machado \& P. G. L. Pena (Orgs.), Saúde do trabalhador na sociedade brasileira contemporânea (pp. 325-343). Rio de Janeiro: Editora Fiocruz.

Centro de Referência Técnica em Psicologia e Políticas Públicas. (2008). Saúde do trabalhador no âmbito da saúde pública: Referências para a atuação do psicólogo. Brasília: CFP. Recuperado de http://crepop.pol.org.br/novo/wp-content/ uploads/2010/11/saude_do_trabalhador_COMPLETO.pdf

Costa, D., Lacaz, F. A. C., Jackson F. J. M., \& Vilela, R. A. G. (2013). Saúde do trabalhador no SUS: Desafios para uma política pública. Revista Brasileira de Saúde Ocupacional, 38(127), 11-21. doi: http://dx.doi.org/10.1590/S0303-76572013000100003

Dias E. C, \& Hoefel M. G. (2005). O desafio de implementar as ações de saúde do trabalhador no SUS: A estratégia da RENAST. Ciência Saúde Coletiva, 10(4), 817-27. doi: http://dx.doi.org/10.1590/S1413-81232005000400007

Franco, T., Druck, G., \& Seligmann-Silva, E. (2010). As novas relações de trabalho, o desgaste mental do trabalhador e os transtornos mentais no trabalho precarizado. Revista Brasileira de Saúde Ocupacional, 35(122), 229-248. doi: http://dx.doi. org/10.1590/S0303-76572010000200006

Jacques C. C., Milanez, B., \& Mattos, R. C. O. C. (2012). Indicadores para Centros de Referência em Saúde do Trabalhador: Proposição de um sistema de acompanhamento de serviços de saúde. Ciência \& Saúde Coletiva, 17(2), 369-378. doi: http:// dx.doi.org/10.1590/S1413-81232012000200011

Lacaz, F. A. D. C. (2013). O campo saúde do trabalhador: Epistemologia, desafios e lacunas. In E. A. S. Lourenço \& V. L. Navarro (Orgs.), O avesso do trabalho III (pp. 219-238). São Paulo: Outras Expressões.

Laurell, A. C. (2009). A saúde-doença como processo social. In E. D. Nunes (Trad.), La salud-enfermedad como proceso social. Revista Latinoamericana de Salud, 2, 7-25. (Original publicado em 1982).

Laurell, A. C., \& Noriega, M. (1989). Processo de produção e saúde: Trabalho e desgaste operário. São Paulo: Cebes/Hucitec.

Lourenço, E. A. S (2013). Alienação e agravos à saúde dos trabalhadores no setor sucroenergético. In E. A. S. Lourenço \& V. L. Navarro (Orgs.), O avesso do trabalho III (pp. 165-198). São Paulo: Outras Expressões.

Machado, J. M. H., Santana, V. S., Campos, A., Ferrite, S., Peres, M. C., Galdino, A., ... Santos, A. P. L (2013). Situação da Rede Nacional de Atenção Integral em Saúde do Trabalhador (RENAST) no Brasil, 2008-2009. Revista Brasileira de Saúde Ocupacional, 38(128), 243-256. doi: http://dx.doi.org/10.1590/S0303-76572013000200012

Mendes, R., \& Dias, E. (1991) Da medicina do trabalho à saúde do trabalhador. Revista Saúde Pública, 25(5), 341-349. doi: http:// dx.doi.org/10.1590/S0034-89101991000500003

Minayo-Gomez, C. M. (2011). Introdução. In C. Minayo-Gomez, J. M. H. Machado \& P. G. L. Pena (Orgs.), Saúde do trabalhador na sociedade brasileira contemporânea (pp. 23-34). Rio de Janeiro: Editora Fiocruz.

Medeiros, M. (2001). O Centro de Referência em Saúde do Trabalhador de Campinas: Trajetória de uma experiência (Dissertação de mestrado). Recuperado de http://www.bibliotecadigital.unicamp.br/document/?code=vtls000219926

Navarro, V. L., \& Padilha, V. (2007). Dilemas do trabalho no capitalismo contemporâneo. Psicologia \& Sociedade, 19(1), 57-65. doi: http://dx.doi.org/10.1590/S0102-71822007000400004

Oddone, I., Marri, G., Gloria, S., Briante, G., Chiattella, M., \& Re, A. (1986). Ambiente de trabalho: A luta dos trabalhadores pela saúde. São Paulo: Hucitec.

Organização Internacional do Trabalho (2013). A prevenção das doenças profissionais. Genebra: OIT. Recuperado de http://www. ilo.org/public/portugue/region/eurpro/lisbon/pdf/safeday2013_relatorio.pdf

Pignati, W. (2013) O processo saúde-trabalho-doença, os sindicatos e os desafios para a vigilância em saúde do trabalhador. In E. A. S. Lourenço \& V. L. Navarro (Orgs.), O avesso do trabalho III (pp. 313-335). São Paulo: Outras Expressões.

Ribeiro, P. H., \& Lacaz, C. F. A. (1984). De que adoecem e morrem os trabalhadores. São Paulo: DIESAT.

Sant'ana, R. S., \& Mustafa P. S. (2013). Assistência social e precarização do trabalho: A perversa opção brasileira. In E. A. S. Lourenço, \& V. L. Navarro (Orgs.), O avesso do trabalho III (pp. 259-278). São Paulo: Outras Expressões. 
Santos, A. P. L. D., \& Lacaz, F. A. (2011). Saúde do trabalhador no SUS: Contexto, estratégias e desafios. In C. Minayo-Gomez, J. M. H. Machado \& P. G. L. Pena (Orgs.), Saúde do trabalhador na sociedade brasileira contemporânea (pp. 87-105). Rio de Janeiro: Editora Fiocruz. 